\title{
Recombinational reassortment among opa genes from ET-37 complex Neisseria meningitidis isolates of diverse geographical origins
}

\author{
Marcia M. Hobbs, ${ }^{1}$ Burkhard Malorny, ${ }^{2}$ Parachuri Prasad, ${ }^{1}$ \\ Giovanna Morelli, ${ }^{2}$ Barica Kusecek, ${ }^{2}$ John E. Heckels, ${ }^{3}$ Janne G. Cannon ${ }^{1}$ \\ and Mark Achtman ${ }^{2}$
}

Author for correspondence: Mark Achtman. Tel: +49 308413 1262. Fax: +493084131387.

e-mail: achtman@mpimg-berlin-dahlem.mpg.de

1 Department of
Microbiology and
Immunology, University of
North Carolina School of
Medicine, Chapel Hill,
NC 27599, USA
2 Max Planck Institut für
molekulare Genetik,
Ihnestrasse 73, D-14195
Berlin, Germany
3 Molecular Microbiology
Group, University of
Southampton Medical
School, Southampton
General Hospital,
Southampton SO9 4XY, UK

\begin{abstract}
Opacity (Opa) proteins are a family of antigenically variable outer-membrane proteins of Neisseria meningitidis. ET-37 complex meningococci, defined by multilocus enzyme electrophoresis, have been isolated on different continents. Twenty-six different Opa proteins have been observed within strains of the ET37 complex isolated between the 1960 s and the 1980s, although individual strains have only four opa genes per chromosome. In this work the opa genes of four closely related ET-37 complex $N$. meningitidis strains recently isolated from Mali, West Africa were characterized and compared with the opa genes of strain FAM18, an ET-37 complex isolate from the USA. DNA sequence analysis and Southern blot experiments indicated that recombinational reassortment, including gene duplication and import by horizontal genetic exchange, has occurred in the opa genes within the ET-37 complex, resulting in two partially different Opa repertoires being present in FAM18 and the Mali isolates. Using synthetic peptides derived from the hypervariable (HV) regions of opa genes, the epitopes for nine mAbs were mapped. These bacteria, isolated on different continents, contain both shared and unique opa HV regions encoding epitopes recognized by $\mathrm{mAbs}$ and show evidence of recombinational reassortment of the HV regions.
\end{abstract}

Keywords: Neisseria meningitidis, gene conversion, opacity protein, hypervariable regions, global gene pool

\section{INTRODUCTION}

Neisseria meningitidis is a common cause of meningitis and septicaemia throughout the world (Peltola, 1983; Achtman, 1995). Meningococci have been classified into serogroups based on the immunological reactivity of the polysaccharide capsule and most isolates from invasive meningococcal disease belong to serogroups A, B or C (Peltola, 1983). Serogroup A meningococci are responsible for epidemics, particularly in sub-Saharan Africa (Olyhoek et al., 1987) and China (Wang et al., 1992),

Abbreviations: ET, electrophoretic type; HV, hypervariable; MLEE, multilocus enzyme electrophoresis.

The GenBank/EMBLDDBJ accession numbers for the $N$. meningtidis $Z 4197$ opa sequences reported in this paper are U37255-U37257 and U77881. The accession numbers for the FAM18 opa sequences are X63108-X63111. whereas endemic disease and limited outbreaks in developed countries are mainly associated with serogroups B and C (Achtman, 1995).

Multilocus enzyme electrophoresis (MLEE) of serogroup $\mathrm{B}$ and $\mathrm{C}$ meningococci has been used to identify three epidemic lineages consisting of related electrophoretic types (ETs) called the ET-5 complex, the ET-37 complex and the A4 cluster (Achtman, 1995). Endemic disease and outbreaks caused by serogroup $\mathrm{C}$ meningococci of the ET-37 complex have been reported during the 1990s from North America (Ashton et al., 1991; Pinner et al., 1991), Europe (Kriz et al., 1994), Brazil (Sacchi et al., 1992) and the Sahel region of West Africa, including Mali (Broome et al., 1983; Wang et al., 1993). Although serogroup B and C bacteria are heterogeneous with regard to the cell surface antigens used for serotyping and serosubtyping, serogroup C, ET-37 
complex bacteria are fairly uniform, even with respect to expression of variable antigens such as porins and pilin (Wang et al., 1993). Endemic disease isolates from Mali, collected from 1989 to 1991 , form a homogeneous group that is related but not identical to other bacteria of the ET-37 complex (Wang et al., 1993).

Characterization of Opa proteins has been useful in detecting microevolution among closely related meningococcal strains (Hobbs et al., 1994; Morelli et al., 1997). Opa proteins are a family of variable outermembrane proteins in N. meningitidis (Stern \& Meyer, 1987; Woods \& Cannon, 1990; Aho et al., 1991; Hobbs et al., 1994; Morelli et al., 1997) and Neisseria gonorrhoeae (Stern et al., 1986; Stern \& Meyer, 1987; Connell et al., 1988, 1990; Murphy et al., 1989; Bhat et al., 1991). Opa expression can influence a variety of neisserial interactions with host cells in vitro (Rest et al., 1985; Makino et al., 1991; Weel et al., 1991; Belland et al., 1992; Kupsch et al., 1993; Virji et al., 1993; Blake et al., 1995; De Vries et al., 1996), and Opa variation occurs during infection with $N$. meningitidis (Woods \& Cannon, 1990; Achtman et al., 1991) and N. gonorrboeae (James \& Swanson, 1978; Swanson et al., 1988; Jerse et al., 1994). Phase variation (reversible on-off switching) of Opa proteins results from alterations in reading frame caused by changes in the number of pentanucleotide repeats (CTCTT) in the signal-peptideencoding region of opa genes (Stern et al., 1986; Stern \& Meyer, 1987; Kawula et al., 1988; Belland et al., 1989, 1997; Murphy et al., 1989). Antigenic variation among the Opa proteins of an individual strain is a consequence of alternate expression from multiple opa loci in the bacterial chromosome, encoding proteins with different antigenic characteristics. Meningococci possess either three or four opa genes, with differences between them occurring mainly in two hypervariable (HV) regions within a conserved framework (Stern \& Meyer, 1987; Aho et al., 1991; Hobbs et al., 1994; Morelli et al., 1997). Several epitopes for $\mathrm{mAbs}$ recognizing surface-exposed determinants and distinguishing between individual Opa proteins have been mapped to HV regions (Connell et al., 1988; Robinson et al., 1988; Aho et al., 1991; Hobbs et al., 1994). At least within serogroup A bacteria, these opa genes are located at widely separated chromosomal loci called opaA, opaB, opaD and opaJ (Dempsey et al., 1995; Morelli et al., 1997).

Twenty-six Opa proteins differing in electrophoretic mobility and/or reactivity with mAbs have been observed within meningococci of the ET-37 complex (Wang et al., 1993), although all ET-37 strains examined also have four opa genes in the chromosome (Aho et al., 1991 and our unpublished observations). Furthermore, only three distinct Opa proteins were expressed by the recent isolates from Mali (Wang et al., 1993). Western blot analysis of outer membranes revealed some antigenic similarities of the Opa proteins from Mali bacteria with those of FAM18, an ET-37 complex strain isolated in North Carolina, USA in 1983 (Wang et al., 1993). Recombinational reassortment of HV regions, gene duplication and import by horizontal genetic exchange can occur among meningococcal opa genes, leading to antigenic variation and differences in the $O p a$ repertoires of clonally related isolates of serogroup A, sub-group IV-1 (Hobbs et al., 1994; Morelli et al., 1997). Horizontal genetic exchange can also result in essentially identical alleles being present in clonally unrelated strains (Maiden et al., 1996). It seemed likely that similar processes of recombination had been responsible for generating the observed variation among Opa proteins expressed by ET-37 complex strains. This study was designed to test that possibility by comparing the sequences of opa genes of serogroup C meningococci of the ET-37 complex from Mali with those from strain FAM18. Because former analyses had used epitopes recognized by $\mathrm{mAbs}$ to compare Opa proteins, we also delineated the continuous B-cell epitopes in the HV regions of these strains.

\section{METHODS}

Bacterial strains. $N$. meningitidis serogroup $\mathrm{C}$ isolates from the United States (FAM18) (Aho et al., 1991) and Mali (Z4183, Z4184, Z4193 and Z4197) (Wang et al., 1993) were previously identified as belonging to the ET-37 complex by MLEE (Wang et al., 1993). Meningococci were grown on GCB agar (Difco), with the supplements of Kellogg et al. (1963), at $37^{\circ} \mathrm{C}$ in a $5 \%$ $\mathrm{CO}_{2}$ atmosphere. E. coli $\mathrm{DH} 5 \alpha \mathrm{F}^{\prime}$ was grown on $\mathrm{LB}$ agar with or without ampicillin $\left(50 \mu \mathrm{g} \mathrm{ml}^{-1}\right)$.

Genetic nomenclature. A listing of former and current designations is presented in Table 1. opa alleles were designated by their chromosomal locus and a unique number assigned to each allele with a unique sequence (Morelli et al., 1997). Opa proteins were assigned the same number as the encoding allele, except that the mature proteins encoded by opaA5200 and opaD5201 are identical and are both referred to as Opa5200 (Table 1).

mAbs. These are listed in Table 2, including the sources of those that had been formerly described. New hybridomas were isolated after immunization of BALB/c mice with heatinactivated serogroup $C$ bacteria from Mali as described by Achtman et al. (1992). After two rounds of cloning by limiting dilution, antibodies were purified from hybridoma supernatants by protein $\mathrm{G}$ affinity chromatography.

Electrophoresis and hybridization techniques. Meningococcal outer membranes were prepared as previously described (Cannon et al., 1984). Proteins were solubilized at $37^{\circ} \mathrm{C}$ in SDS sample buffer and separated by SDS-PAGE in resolving gels containing $11 \%(w / v)$ acrylamide and Laemmli buffer. Western blots were probed with mAbs using a peroxidase-conjugated goat anti-mouse IgG secondary antibody (Sigma) and the Enhanced Chemiluminescent (ECL) detection system (Amersham).

Meningococcal DNA was prepared in agarose blocks, digested with BglII, resolved by contour-clamped homogeneous electric field (CHEF) electrophoresis and transferred and cross-linked to BAS membrane (Schleicher \& Schuell) as previously described (Aho et al., 1991; Dempsey et al., 1991). Southern and plaque blots were performed using hybridization with radiolabelled oligonucleotide probes as previously described (Hobbs et al., 1994).

Cloning and sequencing techniques. The opa genes of strain Z4197 were cloned into M13mp18 from DNA fragments amplified by PCR using primers to conserved sequences 


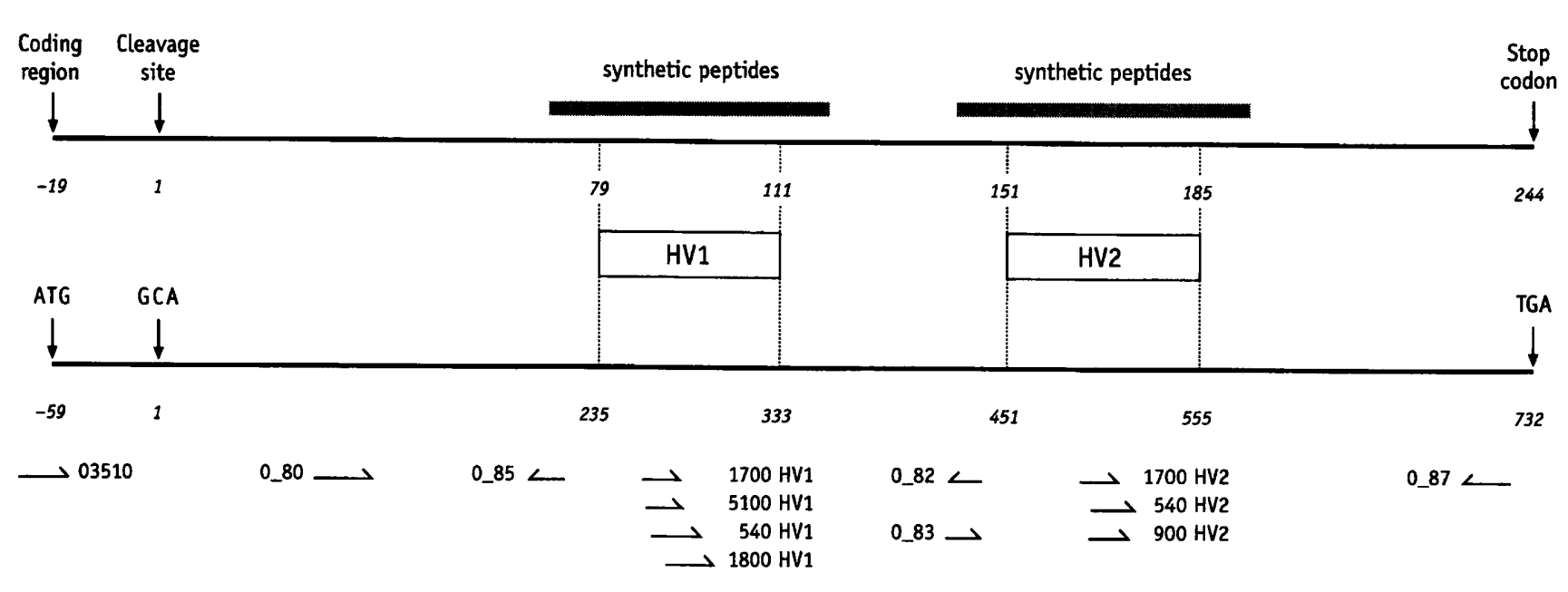

Fig. 1. Map of Opa proteins and opa genes. Top line, Opa proteins, including the signal peptide $(-19$ to -1$)$ and the HV1 and HV2 regions from which peptides were synthesized. Numbers correspond to amino acids. Bottom line, opa genes and locations of oligonucleotides used. Numbers correspond to nucleotides.

flanking meningococcal opa genes as previously described (Hobbs et al., 1994). Plaque blots were screened with oligonucleotide probes derived from the HV1 and HV2 regions of the opa genes of strain FAM18 (Aho et al., 1991) to identify clones containing individual opa genes from Z4197. Singlestranded phage DNA was sequenced by dideoxy chaintermination with the Sequenase system (USB) using the M13 forward sequencing primer and opa-specific internal primers (MH1-MH4) as previously described (Hobbs et al., 1994). Two to four independently isolated clones were sequenced for each opa locus.

We used HV-specific oligonucleotides (Fig. 1) from FAM18 opa sequences that were present in the opa genes of Z4197 [540 HV1， 5' GTTACTGAAGATATAGCAGAC 3'; 540 HV2, 5' GACGGCAACCTCTCCACAGGGAGG 3'; 900 HV2, 5' CAGGGGTTGGCGTTACAGAGCC $3^{\prime} ; 1700$ HV1, $5^{\prime}$ CAAAAGAGTTGGAAAACAAGC 3'; $1700 \mathrm{HV} 2$, Aho et al. (1991); 1800 HV1, 5' AGAAACCCAGGACAATAGGG $\left.3^{\prime}\right]$ and an oligonucleotide derived from the HV1 sequence in opa5100 from Z4197 (5100 HV1, 5' GCAGAAAATAGAGATAATGC $3^{\prime}$ ) as radiolabelled probes in Southern blot analysis of Z4197 DNA to confirm that the PCR-generated clones represented sequences present in the chromosome. We did obtain some clones with HV1/HV2 combinations not found in the chromosome (data not shown); these may have been artefacts generated by PCR and were not analysed further. DNA sequences were analysed using GCG software (Genetics Computer Group, Madison, WI, USA, version 8).

Direct sequencing of individual opa genes. BglII fragments containing opa genes were excised from pulsed-field gels and the agarose slices were digested with $\beta$-agarase according to the manufacturer's instructions (New England Biolabs). PCR amplification of the opa genes $\left(30 \mathrm{cycles}\right.$ of $1 \mathrm{~min}$ at $95^{\circ} \mathrm{C}$, $1 \mathrm{~min}$ at $57^{\circ} \mathrm{C}$ and $1 \mathrm{~min}$ at $72^{\circ} \mathrm{C}$, followed by $10 \mathrm{~min}$ at $\left.72^{\circ} \mathrm{C}\right)$ was performed with the primers $\mathrm{O} 3510\left(5^{\prime} \mathrm{TACGCT}\right.$ GCAGAAAATGAATCCAGCCCCC $\left.3^{\prime}\right)$ and O87 (5' GCGCACGCCCAATGAGACTTCGTGGG $3^{\prime}$ ) (Fig. 1). The PCR products were adjusted to $12.5 \%$ (w/v) PEG 8000 (Sigma), $1.6 \mathrm{M} \mathrm{NaCl}$ and precipitated at $37^{\circ} \mathrm{C}$ for $10 \mathrm{~min}$. The pellet was harvested by centrifugation in a microfuge for $10 \mathrm{~min}$, washed with $80 \%(\mathrm{v} / \mathrm{v})$ ethanol, centrifuged again and dried. The pellet was dissolved in water and sequenced from both strands by automated cycle sequencing (ABI 377) using the oligonucleotide primers O3510, O83 (5' GCGCGTCGCCTACGGAC $\left.3^{\prime}\right)$, O80 (5' AAGCAACCGGTGCAAACAACACAAGC $\left.3^{\prime}\right)$, O82 ( $5^{\prime}$ TGTCCGTAGGCGACGCGC $\left.3^{\prime}\right)$, O85 ( $5^{\prime}$ GGCATAATCTGCCGCTATCC $\left.3^{\prime}\right)$ and O87. Individual strands were sequenced from independent PCR products.

opa loci. The chromosomal loci of the individual alleles were assigned as described by Morelli et al. (1997). Briefly, for each opa locus, PCR amplification was performed using a conserved oligonucleotide primer from the $\mathrm{N}$-terminal opa region plus a primer from a unique downstream flanking sequence. These PCR products were sequenced as above.

Epitope mapping. Multiple synthetic $\mathrm{N}$-terminally acetylated peptides were synthesized on pins as previously described (Geysen et al., 1987), using an Epitope Scanning Kit (Cambridge Research Biochemicals) with a dilution aid (Epiguide, Labsystems) and the modifications of McGuinness et al. (1990). The pins were screened by ELISA for reactivity after incubation for $90 \mathrm{~min}$ with $\mathrm{mAbs}$ diluted to $1-10 \mu \mathrm{g} \mathrm{ml}^{-1}$. Reactivity was detected using alkaline-phosphataseconjugated, affinity-purified rabbit immunoglobulins to mouse immunoglobulins (Dakopatts) as previously described (Achtman et al., 1992).

\section{RESULTS}

N. meningitidis strain FAM18 can express four electrophoretically distinguishable Opa proteins, OpaA through OpaD (Woods \& Cannon, 1990). The sequences of the four opa genes from strain FAM18 contain four distinct versions of HV1, three distinct versions of HV2 and two minor variants of one of the HV2 versions which differ by three nucleotides (Aho et al., 1991; see below). Wang et al. (1993) demonstrated that serogroup C meningococci of the ET-37 complex isolated between December 1989 and March 1990 in Mali, West Africa expressed three Opa proteins with similar electrophoretic mobilities to those of the FAM18 Opa proteins and that some $\mathrm{mAbs}$ recognized epitopes 


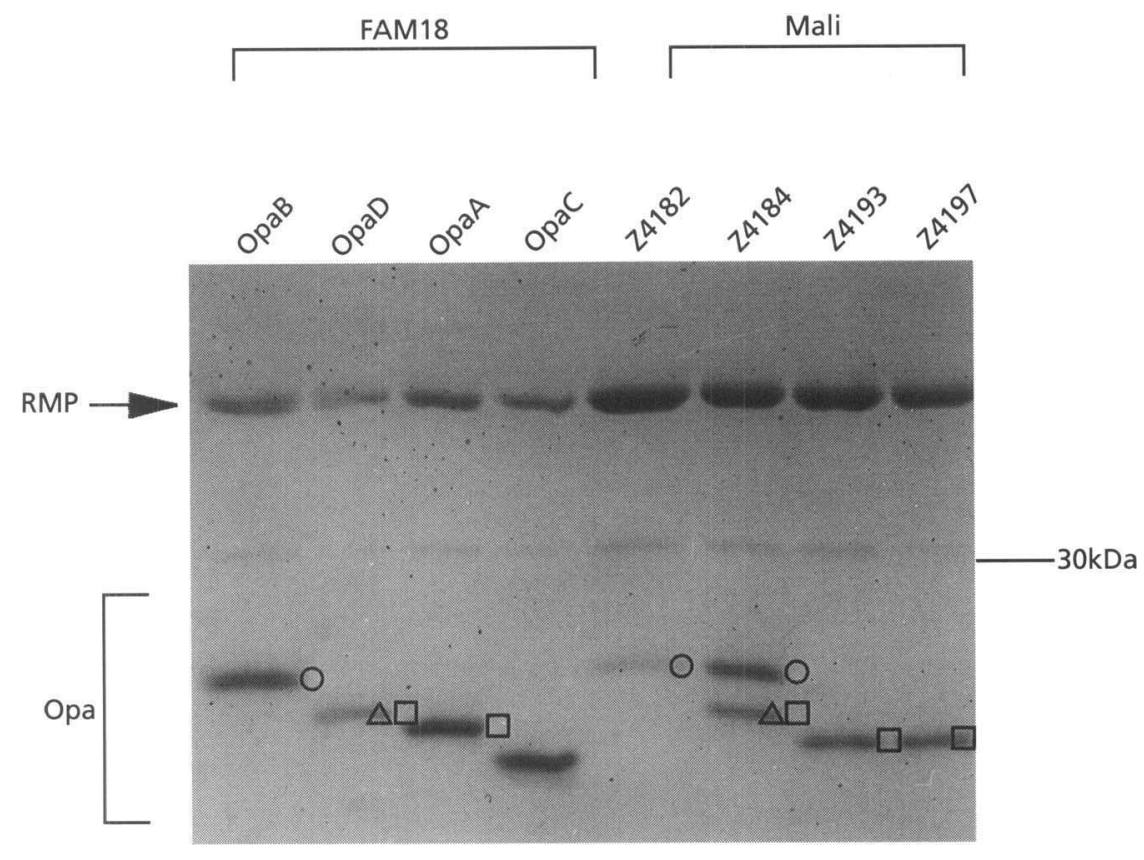

Fig. 2. Immunoreactivity of Opa proteins expressed by ET-37 complex $N$. meningitidis isolates. Outer-membrane proteins were solubilized at $37^{\circ} \mathrm{C}$, separated by SDS-PAGE and stained with Coomassie brilliant blue. The results from Western blots with the same preparations are summarized by symbols indicating reactivity of individual Opa proteins with mAbs H.21 (circles), H.22 (squares) and 7-24-D9 (triangles). RMP, reduction modifiable protein, also known as Class 4 protein.

Table 1. Designations of opa genes, clones and Opa proteins

$\begin{array}{|clllll|}\hline \text { Strain } & \text { opa gene } & \text { Clone } & \multicolumn{2}{c|}{\text { Opa protein }} & \text { Reference } \\$\cline { 3 - 5 } & & & $\left.\begin{array}{c}\text { Former } \\ \text { name }\end{array} & \begin{array}{c}\text { Current } \\ \text { name }\end{array} & \\ \hline \multirow{2}{*}{\text { FAM18 }} & \text { opaA1800 } & \text { pFLOB1800 } & \text { OpaA } & \text { Opa1800 } \\ & \text { opaB900 } & \text { pFLOB900 } & \text { OpaC } & \text { Opa900 } \\ & \text { opaD1700 } & \text { pFLOB1700 } & \text { OpaB } & \text { Opa1700 } \\ & \text { opaJ540 } & \text { pFLOB540 } & \text { OpaD } & \text { Opa540 }\end{array}\right\}$ (1991)

* The opaD5201 allele was not cloned.

on the Opa proteins from both sets of strains. These results were confirmed using SDS-PAGE and Western blot analysis with outer membranes from variants of strain FAM18 expressing each of the four Opa proteins and from four independent, representative ET-37 isolates from Mali (Fig. 2). We tested reactivity with a total of nine mAbs that react with one or more Opa proteins in these strains, including mAbs secreted by four newly isolated Opa-specific hybridomas. These mAbs can be assigned to five classes based on the Opa proteins with which they react in Western blots and the epitopes they recognize (see below). Together with the electrophoretic data, the results confirmed that the Mali strains expressed a total of three Opa proteins that exhibited similar electrophoretic mobility and $\mathrm{mAb}$ binding to three of the four Opa proteins from FAM18 (P5.III- $\alpha$ and OpaB; P5.IIb- $\alpha$ and OpaD; P5.IIa- $\alpha$ and OpaA). A protein resembling the FAM18 OpaC protein was not observed in outer-membrane preparations from ET-37 meningococci from Mali.

As a consequence of the variability of opa gene sequences between different meningococcal strains, opa gene and Opa protein nomenclature has become confusing and partially repetitive. We will henceforth refer to opa alleles by unique numbers which in this case also reflect the clones which were sequenced (Table 1). The new protein designations also include the corresponding allele numbers rather than letters as in the past. Table 1 presents a summary of the designations of the opa alleles, Opa proteins and clones used in this study.

Reactivity of Opa proteins from different isolates with a given $\mathrm{mAb}$ indicates the presence of an epitope with a 
(a)

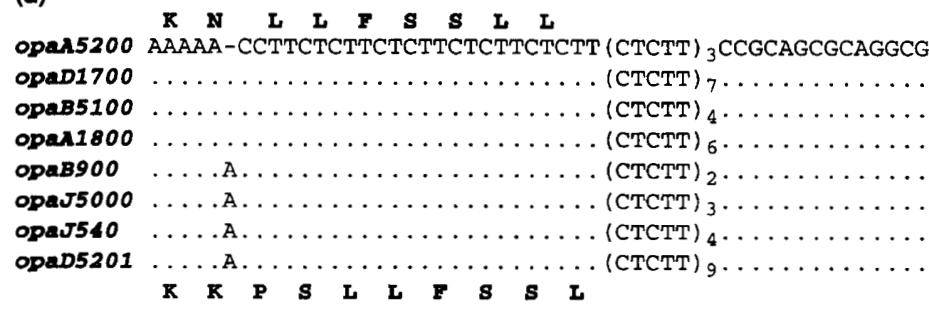

(c)

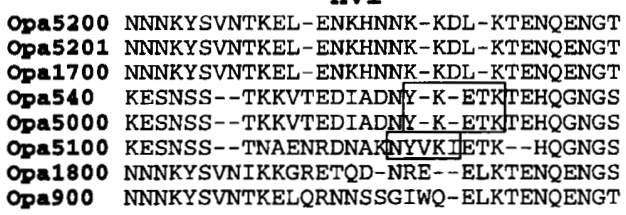

HV2

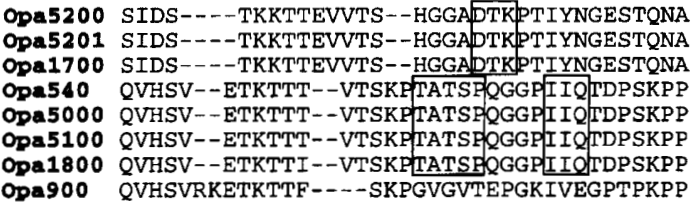

(b)

HV1

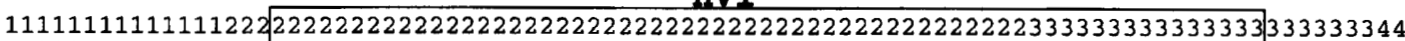
1112256788900000011166789023334444555555666666666777777777788888888999999999000000011122333444599900 3680216658705678901358464151780268234589023456789012345678902346789012345678134567923613023458178901 opaA5200 AGGAGTTGAGGAC-_-_-CCGGTAACACACAAACGTCCACAAAGAGTTGGAAAACAAGCTAAAATAAG-_.--AGCCTGAGGGAGATCA CTTT_-_-_

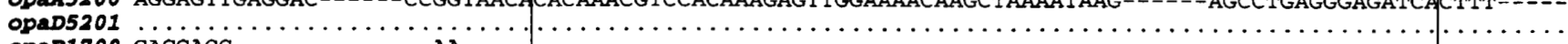

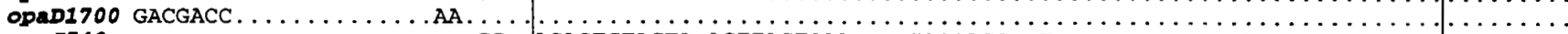

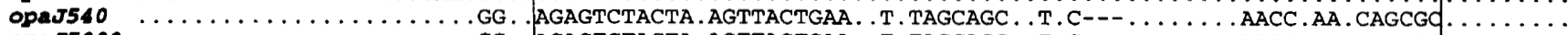

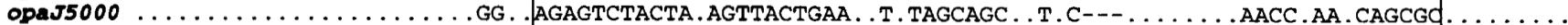

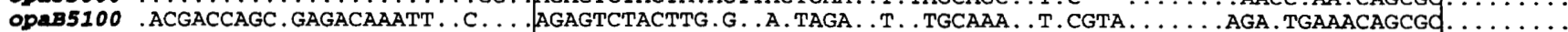

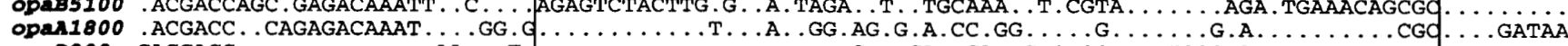

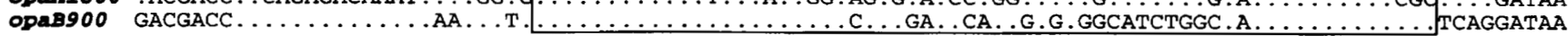

HV2

444444444444444444444444444444444444444444555555555555555555555555555555555555555555555555555666667 000023445555555666666777777788888899999999000000000111111112222222233333333344444444555567789023572 234508460123467234567012378912457801245689013456789123456780123458901245678901234567012383708947465 opan5200 ---TACGAAGCACGGACCAAAAACAGAGTGTACTCC---CCATGTGGTGCGACACAAACCTACGTTATATGGGGAAATACGCAACGCCCCGCGCTGA

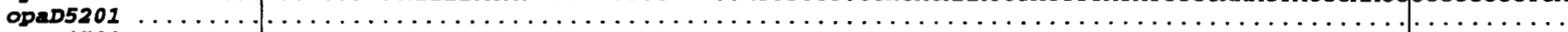

Fig. 3. Sequence variation of opa alleles and Opa proteins. (a) Consensus nucleotide and amino acid sequences in the region encoding the signal peptide. (b) Sequence polymorphisms in the region encoding the mature Opa proteins. Only polymorphic sites are shown, with the nucleotide position indicated by vertical numbers. The HV1 and HV2 hypervariable regions are boxed. (c) Amino acid polymorphisms in the HV1 and HV2 regions. Epitopes recognized by mAbs are boxed. Points indicate identity to the consensus except in (c) where all amino acids are shown; dashes indicate deletions.

high degree of homology, usually located within an HV region. Thus, shared reactivity with a single $\mathrm{mAb}$ suggests, but does not prove, that different Opa proteins contain the same $\mathrm{HV}$ region in which the $\mathrm{mAb}$ epitope is encoded. Likewise, reactivity with both HV1- and HV2specific mAbs suggests the presence of the same HV1 and $\mathrm{HV} 2$ regions in different Opa proteins. However, even Opa proteins that are indistinguishable electrophoretically and in reactivity with mAbs might differ to some extent in sequence, especially considering the different sources of the bacteria and the variability of Opa proteins identified within the ET-37 complex meningococci from different countries. In addition, the analysis of Opa proteins by $\mathrm{mAbs}$ is limited to the products of the genes expressed at a given time. Because Opa expression is subject to phase variation, the absence of a particular Opa protein at the time of analysis does not necessarily indicate its absence from the repertoire of an isolate.

\section{Sequences of opa genes}

Since Opa proteins expressed by the Mali isolates reacted with mAbs recognizing $\mathrm{HV}$-encoded epitopes present in the opa genes of strain FAM18, we used oligonucleotides derived from FAM18 HV sequences to probe Southern blots of Z4197 DNA digested with BglII. An oligonucleotide probe specific for the $5^{\prime}$ repeat region of opa genes $\left(\mathrm{CTCTT}_{\mathrm{n}}\right.$ ) identified four opa loci in the chromosome of the West African strain, present on BglII restriction fragments of similar size to those from FAM18 (data not shown). Two BglII fragments reacted with the HV1 probe derived from opa1700, raising the possibility that a duplication of one gene had occurred. Such a duplication could account for only three different Opa proteins having been detected by Western blots of isolates from Mali. The other hybridization patterns were fully consistent with the sequence results presented below (data not shown). 

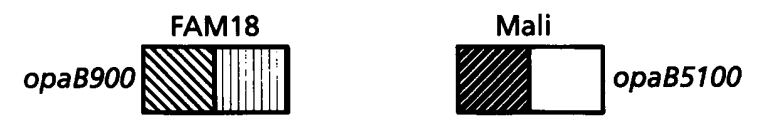

opaD1700
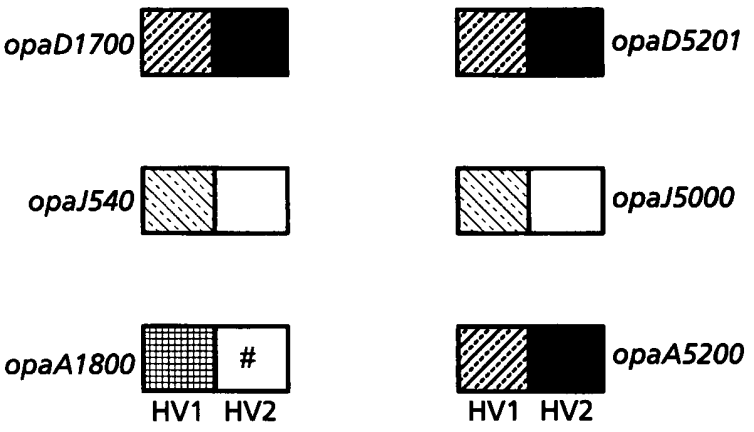

Fig. 4. Schematic representation of opa genes in ET-37 complex meningococcal isolates. The order of the alleles from top to bottom parallels the decreasing sizes of the Bg/ll fragments. Four independent isolates from Mali (Z4182, Z4184, Z4193 and Z4197) were identical by Southern blot analysis with HV-specific oligonucleotide probes (data not shown). Paired boxes indicate sequences present in the HV1 and HV2 regions of each opa gene. Each pattern represents a different version of an HV sequence. \#, three different base pairs in the HV2 sequence of opaA1800 versus opaJ540, opaJ5000 or opaB5100.

Table 2. Reactivities of mAbs with Opa proteins

\begin{tabular}{|c|c|c|c|}
\hline Antibody* & Opa protein & HV region & $\begin{array}{c}\text { Minimal } \\
\text { epitope }\end{array}$ \\
\hline $\begin{array}{l}\text { H.21 }{ }^{a} \text {, } \\
\text { AG612 }^{b} \text {, } \\
\text { AG606 }^{b}\end{array}$ & $\left.\begin{array}{l}\text { Opa1700, } \\
\text { Opa5200 }\end{array}\right\}$ & HV2 & DTK \\
\hline $\begin{array}{l}\text { H.22 } \\
\text { AG108 } \\
\text { AF313 }\end{array}$ & $\left.\begin{array}{l}\text { Opa } 1800, \\
\text { Opa540, } \\
\text { Opa5100, } \\
\text { Opa5000 }\end{array}\right\}$ & HV2 & TATSP \\
\hline $15-1-\mathrm{P} 5.5^{c}$ & $\left.\begin{array}{l}\text { Opa } 1800, \\
\text { Opa540, } \\
\text { Opa5100, } \\
\text { Opa5000 }\end{array}\right\}$ & HV2 & IIQ \\
\hline $7-24-\mathrm{D9}^{c}$ & $\left.\begin{array}{l}\text { Opa540, } \\
\text { Opa5000 }\end{array}\right\}$ & HV1 & YKETK \\
\hline $9-1-\mathrm{P} 5.4^{c}$ & Opa5100 & HV1 & NYVKI \\
\hline
\end{tabular}

* References or source: $a$, Aho et al. (1991); $b$, this study; $c$, Wang et al. (1993).

To further characterize the Opa repertoire of ET-37 complex meningococci from Mali, the opa genes of strain Z4197 were cloned into M13mp18. Clones containing opa genes corresponding to the different $\mathrm{HV}$ combinations present on the CTCTT-binding BglII fragments were identified in plaque blots with the FAM18 HV oligonucleotide probes, and inserts were sequenced from single-stranded phage DNA. Only three different opa sequences were obtained. Southern blot analysis with $\mathrm{HV}$-specific probes, including the novel HV1 region from opa5100 (see below), indicated the same distribution of HV sequences in three other Mali isolates belonging to the ET-37 complex as in strain Z4197 (data not shown). To ensure that these sequences corresponded to all four opa loci, the BglII fragments containing opa alleles were excised from pulsed-field agarose gels, and the opa genes amplified by PCR and sequenced directly. Finally, to determine the chromosomal loci of the individual alleles (Dempsey et al., 1995, Morelli et al., 1997), the four opa alleles from both FAM18 and from Z4197 were sequenced from PCR products generated using primers from unique regions flanking each opa locus in serogroup A bacteria. PCR products were obtained for all four loci and the sequences were the same as those obtained from excised $B g l \mathrm{II}$ fragments, showing that the opa alleles in ET-37 complex bacteria are located at the same chromosomal locations as those in serogroup A. The complete designation of each opa allele, including the chromosomal location, is shown in Table 1 and a summary of the sequence variability between these different opa alleles is presented in Fig. 3. The complete coding sequences of the Z4197 opa genes have been deposited in the EMBL/GenBank/DDBJ nucleotide sequence data libraries under accession numbers U37255-U37257 and U77881. The sequences obtained for the opa alleles from FAM18 were longer than those originally available and also corrected some minor sequence errors. They have been deposited under the original accession numbers X63108-X63111.

In agreement with the hybridization data, two of the opa alleles from strain Z4197, opaA5200 and opaD5201, were identical (Fig. 3b), except for the region encoding the signal peptide where the number of CTCTT repeats differed and the poly(A) stretch directly preceding the CTCTT repeats was one nucleotide shorter (five As) in opaA5200 (Fig. 3a). The shorter poly(A) stretch was also present in opaD1700, opaB5100 and opaA1800 and results in in-frame translation when the number of CTCTT repeats is $2,5,8$, etc. as opposed to the pattern of $3,6,9$, etc. associated with in-frame translation in opaB900, opaJ5000, opaJ540, opaD5201 and most other opa alleles that have been sequenced (Morelli et al., 1997). Due to the CTCTT repeats, the frameshift introduced by the shorter poly(A) stretch only changes the signal peptide sequence of opa proteins by three amino acids and does not affect the sequence of the mature proteins (Fig. 3a). Within strain Z4197, only opaB5100 was in-frame and only Opa5100 was expressed (Fig. 1).

\section{Translocation and import of opa alleles}

Part of the HV1 region (nucleotides 237-255) and the sequences $(316-654)$ from the end of HV1 to near the $3^{\prime}$ end of the gene were identical between opaB5100 and 

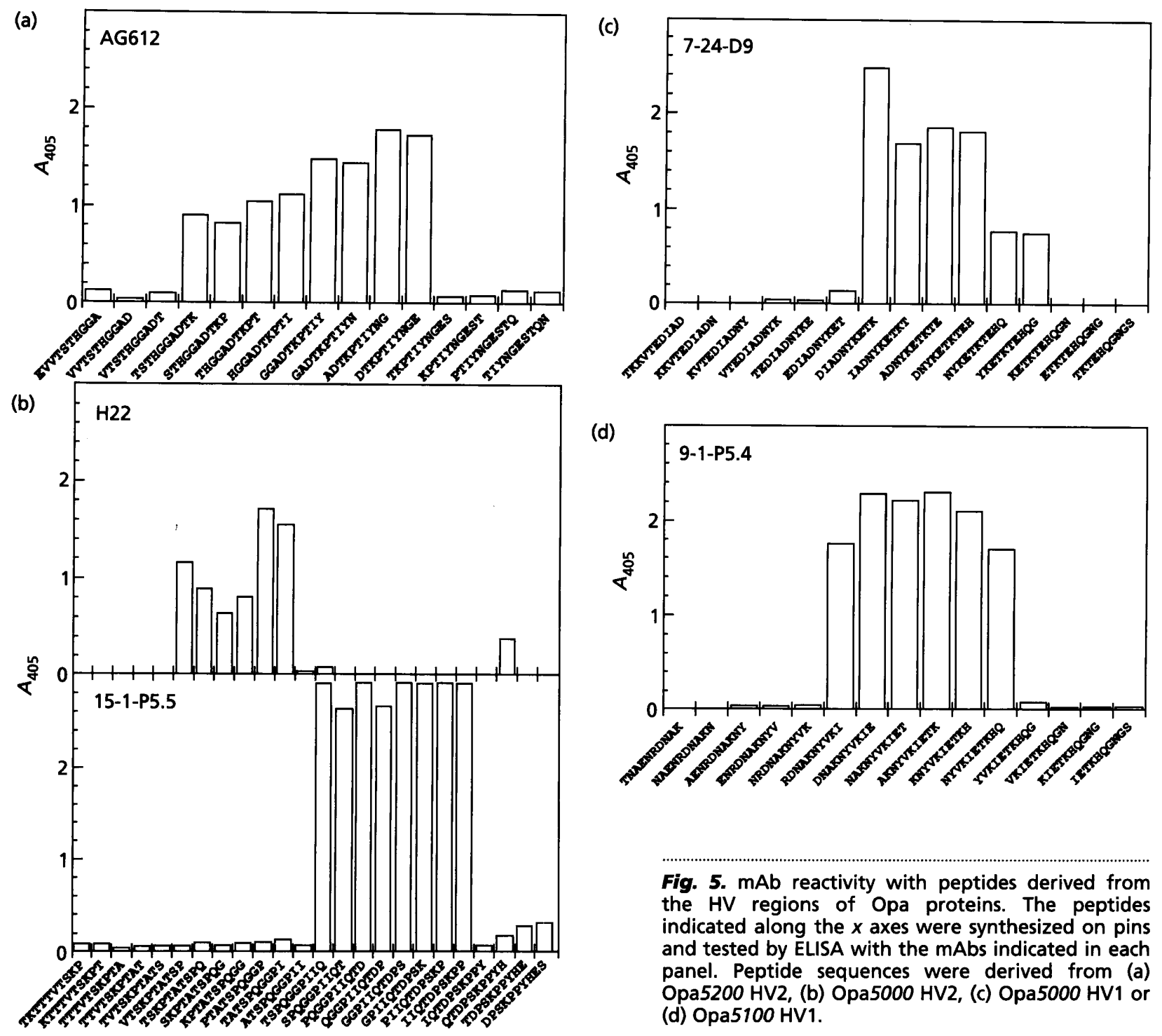

opaJ5000 from strain Z4197 (Fig. 3a, Fig. 4). These identities probably reflect partial gene conversion since these alleles differed extensively at their $5^{\prime}$ ends and throughout most of the HV1 region (Fig. 3a). Because opaJ5000 (strain Z4197) is identical to opaJ540 (FAM18), except for the number of CTCTT repeats (Fig. 3), it seems likely that the sequence at the opaJ locus is ancestral and that the stretches from 237 to 255 and 316 to 654 had translocated from the opaJ locus to the opaB locus. Similarly, opaD5201 (Z4197) is identical to opaD1700 (FAM18) in the region promoter distal to nucleotide 186 (Fig. 3 b), suggesting that the opaD locus is ancestral and that the almost identical opaA5200 allele arose by translocation from the opaD locus. Similar translocation events may account for the distinct polymorphisms between nucleotides 13 and 174 characteristic of $o p a B 900$ and $o p a D 1700$ of FAM18.

A large part of HV1 (259-351) differs between opaB900 (FAM18) and opaB5100 (Z4197) as well as from the other opa alleles in these two strains and cannot have arisen by translocation. These differences between $o p a B 900$ and opaB5100 are also too extensive to have arisen by accumulation of mutations and at least one of these regions must have been imported by horizontal genetic exchange, presumably via transformation with DNA from unrelated neisseriae (Maiden et al., 1996). The remainder of the differences between these two alleles can be attributed to translocation in an ancestor of Z4197 (see above). An independent translocation event in an ancestor of strain FAM18 may have resulted in the similar HV2 regions of opaJ540 and opaA1800 (Fig. 3b, Fig. 4). These alleles differ by only four nucleotides between 444 and 598. Three of these polymorphisms are in the HV2 region and one results in an amino acid change (Fig. 3b, c).

As a result of the putative translocation and import events, FAM18 and Z4197 differ extensively at the opaA and $o p a B$ loci. Although the HV1 and HV2 regions are identical at the opaD locus, the $5^{\prime}$ end of these alleles differed in nine nucleotides resulting in four amino acid differences and the only locus containing identical alleles in the two strains was opaJ. 


\section{Epitope localization}

Previous studies showed that $\mathrm{mAbs}$ which distinguished among Opa proteins recognized epitopes which were encoded within the HV regions and exposed on the bacterial cell surface (Connell et al., 1988; Robinson $e t$ al., 1988; Aho et al., 1991; Hobbs et al., 1994). To map the epitopes recognized by the mAbs in Table 2 more precisely, we tested antibody binding to overlapping peptides, synthesized according to the sequences of the $\mathrm{HV}$ regions of the Opa proteins from Mali. 12-mers overlapping by nine amino acids were synthesized on pins and tested for reactivity with all the mAbs. Each $\mathrm{mAb}$ reacted specifically with a single $\mathrm{HV}$ region which corresponded to its specificity for Opa proteins. None of the mAbs reacted with peptides derived from the HV1 region of opaA5200 or opaD5201, whereas at least one antibody reacted with all other $\mathrm{HV}$ regions tested. Synthetic 10 -mers overlapping by nine amino acids were then made to cover the reacting regions and tested again to determine the minimal binding sites (Fig. 3c, Fig. 5). Each of the minimal binding sites was contained within the region that reacted in the first set of peptides. Five minimal peptide sequences were recognized by the nine $\mathrm{mAbs}$ and formed the basis of their assignment to the classes in Table 2. Within an epitope class in Table 2, different hybridoma cell lines had the same minimal binding sites, but sometimes differed in detailed specificity as indicated by the intensities of reactions with individual peptides (data not shown).

MAb 15-1-P5.5 recognized the HV2 region from the same Opa proteins (Opa540, Opa1800, Opa5000, Opa5100) as H.22, AG108 or AF313, but reacted with a different, non-overlapping minimal sequence (IIQ versus TATSP) (Fig. 3c, Fig. 5b).

\section{DISCUSSION}

According to results from MLEE, N. meningitidis is characterized by great genetic diversity (Caugant et al., 1987). DNA transformation often leads to recombination and genetic shuffling (Spratt et al., 1995), and similarity of isolates based on MLEE does not necessarily indicate clonal relationships within the pathogenic neisseriae (O'Rourke \& Spratt, 1994). However, serogroup A (Wang et al., 1992) and some serogroup B and C bacteria, including those of the ET-37 complex (Wang et al., 1993), do belong to well-defined clonal groupings which are repeatedly isolated from cases of disease in different countries (Achtman, 1995). Even within these clonal groups, limited variation of certain variable antigens such as porins, LOS, pilin and Opa proteins has been noted (Achtman et al., 1992; Wang et al., 1992, 1993; Suker et al., 1994, Morelli et al., 1997). It is likely that recombination and/or horizontal genetic exchange events have been responsible for generating the 26 distinguishable Opa proteins among isolates of the ET37 complex.

We previously demonstrated diversity due to recombinational reassortment of HV regions in the opa genes of serogroup A sub-group IV-1 meningococci isolated from a single epidemic (Hobbs et al., 1994). Subsequent analysis of a larger group of isolates has shown a predominant single Opa repertoire among these bacteria (unpublished data) as well as within sub-group III bacteria from different epidemics (Morelli et al., 1997). However, changes in opa alleles accumulate over decades, leading to major differences between the repertoires of older and younger isolates (Hobbs et al., 1994, Morelli et al., 1997). Many of the observed changes in the Opa repertoire reflect gene conversion resulting in duplication of parts or of complete opa alleles. Such recombination can result in new combinations of individual antigenic determinants encoded by $\mathrm{HV}$ regions which could then potentially be transmitted to other strains by horizontal genetic exchange. The present analysis demonstrates that similar recombinational events have occurred between opa genes during microevolution of isolates belonging to the ET37 complex, resulting in two somewhat different Opa repertoires being present in FAM18 and the isolates from Mali. The results show that opa gene duplication by translocation occurred within a strain that was ancestral to the Mali isolates and that horizontal genetic exchange resulted in the presence of different HV1 regions in the two repertoires. Nevertheless, four different $\mathrm{HV}$-encoded antigenic determinants are shared in both repertoires (Fig. 4). The mAbs H.22, H.21, 9-1-P5.4 and 7-24-D9 react with $\mathrm{HV}$-encoded Opa epitopes in numerous additional strains of the ET-37 complex from geographically diverse sources (Wang et al., 1993). Thus, it seems likely that opa sequences related to those in FAM18 and the Mali isolates are present in ET-37 bacteria from diverse sources.

Horizontal genetic exchange can result in identical or almost identical genes in unrelated meningococci and such observations have been summarized within the concept of a global gene pool (Maiden et al., 1996). The HV1 region of the opaD1700, opaD5201 and opaA5200 alleles differ by only one nucleotide from that of the opaB133 allele of a serogroup A, sub-group IV-1 strain (Hobbs et al., 1994; Morelli et al., 1997). Similarly, the opaB95 allele in a serogroup I strain differs by only a few nucleotides from the opaB94 allele in serogroup A, subgroup III bacteria (Maiden et al., 1996, Morelli et al., 1997). The data presented here reveal another example of this phenomenon: opaJ5200 from the Mali bacteria differs by only one nucleotide from opaB5202, found in a serogroup A, sub-group III strain isolated in Sweden in 1978 (accession number AF001203, Morelli et al., 1997). These observations suggest that the opa genes described here will also be occasionally found in other genetically unrelated neisserieae.

Opa antigenic determinants have largely been defined on the basis of binding of murine mAbs. The extent to which these epitopes resemble the regions of Opa proteins that generate humoral immune responses in humans is not known. Human antibodies to PorA porin, Opc protein and IgA1 protease can recognize epitopes that overlap with those recognized by murine mAbs (de Cossio et al., 1992; Delvig et al., 1994; Morelli et al., 
1994), although the detailed epitopes recognized differed between the human and murine antibodies. The information presented here on the minimal binding sites recognized by murine mAbs may facilitate analysis of epitopes on Opa proteins recognized by sera from convalescent patients in Mali.

The functional significance of Opa antigenic variation is not understood. Virji et al. (1993) demonstrated differences in in vitro adherence and invasion between meningococci expressing different Opa proteins. There may be selective pressures maintaining opa sequences required for bacterial interactions with host cells in vivo; because $\mathrm{HV}$ regions encode exposed portions of Opa proteins, they may well be involved in such interactions. It seems unlikely that the sequence of individual HV regions suffices to account for the efficiency of these interactions, because Opa proteins sharing HV1 or HV2 regions can differ in efficiency of adherence and invasion (Virji et al., 1993), and conformational interactions within the folded protein are probably crucial for bacteria-host interactions. Our comparison of the opa genes of FAM18 and the Mali isolates demonstrates that the Opa900 protein of FAM18 is not essential for infection; nor is the HV1-encoded determinant of Opa1800 (FAM18), because meningococci from Mali lacking these opa gene sequences were capable of causing disease. Similarly, the HV1 region of Opa5100 from the Mali bacteria cannot be essential because FAM18 lacked this sequence. The overall antigenic diversity of meningococcal Opa proteins from unrelated bacteria suggests that a variety of primary amino acid sequences are capable of fulfilling the structural requirements for Opa function(s).

\section{ACKNOWLEDGEMENTS}

This work was supported by NIH Grant AI123830 to J. G. C. and DFG grant Ac36/6-2 to M.A.

\section{REFERENCES}

Achtman, M. (1995). Global epidemiology of meningococcal disease. In Meningococcal Disease, pp. 159-175. Edited by K. Cartwright. Chichester: John Wiley.

Achtman, M., Wall, R. A., Bopp, M., Kusecek, B., Morelli, G., Saken, E. \& Hassan-King, M. (1991). Variation in Class 5 protein expression by serogroup A meningococci during a meningitis epidemic. J Infect Dis 164, 375-382.

Achtman, M., Kusecek, B., Morelli, G., Eickmann, K., Wang, J., Crowe, B., Wall, R. A., Hassan-King, M., Moore, P. S. \& Zollinger, $W$. (1992). A comparison of the variable antigens expressed by clone IV-1 and subgroup III of Neisseria meningitidis serogroup A. J Infect Dis 165, 53-68.

Aho, E. L., Dempsey, J. A., Hobbs, M. M., Klapper, D. G. \& Cannon, J. G. (1991). Characterization of the opa (class 5) gene family of Neisseria meningitidis. Mol Microbiol 5, 1429-1437.

Ashton, F. E., Ryan, J. A., Borczyk, A., Caugant, D. A., Mancino, L. \& Huang, D. (1991). Emergence of a virulent clone of Neisseria meningitidis serotype $2 \mathrm{a}$ that is associated with meningococcal group C disease in Canada. J Clin Microbiol 29, 2489-2493.
Belland, R. J., Morrison, S. G., van der Ley, P. \& Swanson, J. (1989). Expression and phase variation of gonococcal P.II genes in Escherichia coli involves ribosomal frame-shifting and slippedstrand mispairing. Mol Microbiol 3, 777-786.

Belland, R. J., Chen, T., Swanson, J. \& Fischer, S. H. (1992). Human neutrophil response to recombinant neisserial Opa proteins. $\mathrm{Mol}$ Microbiol 6, 1729-1737.

Belland, R. J., Morrison, S. G., Carlson, J. H. \& Hogan, D. M. (1997). Promotor strength influences phase variation of neisserial opa genes. Mol Microbiol 23, 123-135.

Bhat, K. S., Gibbs, C. P., Barrera, O., Morrison, S. G., Jahhnig, F., Stern, A., Kupsch, E.-M., Meyer, T. F. \& Swanson, J. (1991). The opacity proteins of Neisseria gonorrboeae strain MS11 are encoded by a family of 11 complete genes. Mol Microbiol 5, 1889-1901.

Blake, M. S., Blake, C. M., Apicella, M. A. \& Mandrell, R. E. (1995). Gonococcal opacity: lectin-like interactions between Opa proteins and lipooligosaccharide. Infect Immun 63, 1434-1439.

Broome, C. V., Rugh, M. H., Yada, A. A., Giat, L., Giat, H., Zeltner, J. M., Sanborn, W. R. \& Fraser, D. W. (1983). Epidemic group C meningococcal meningitis in Upper Volta, 1979. Bull WHO 61, 325-330.

Cannon, J. G., Black, W. J., Nachamkin, I. \& Stewart, P. T. (1984). Monoclonal antibody that recognizes an outer membrane antigen common to the pathogenic Neisseria species but not to most nonpathogenic Neisseria species. Infect Immun 43, 994-999.

Caugant, D. A., Mocca, L. F., Frasch, C. E., Frøholm, L. O., Zollinger, W. D. \& Selander, R. K. (1987). Genetic structure of Neisseria meningitidis populations in relation to serogroup, serotype, and outer membrane protein pattern. J Bacteriol 169, 2781-2792.

Connell, T. D., Black, W. J., Kawula, T. H. \& 7 other authors (1988). Recombination among protein II genes of Neisseria gonorrboeae generates new coding sequences and increases structural variability in the protein II family. Mol Microbiol 2, 227-236.

Connell, T. D., Shaffer, D. \& Cannon, J. G. (1990). Characterization of the repertoire of hypervariable regions in the protein II (opa) gene family of Neisseria gonorrboeae. Mol Microbiol 4, 439-449.

de Cossio, M. E. F., Ohlin, M., Llano, M., Selander, B., Cruz, S., del Valle, J. \& Borrebaeck, C. A. K. (1992). Human monoclonal antibodies against an epitope on the class $5 \mathrm{c}$ outer membrane protein common to many pathogenic strains of Neisseria meningitidis. J Infect Dis 166, 1322-1328.

De Vries, F. P., Van der Ende, A., van Putten, J. P. M. \& Dankert, J. (1996). Invasion of primary nasopharyngeal epithelial cells by Neisseria meningitidis is controlled by phase variation of multiple surface antigens. Infect Immun 64, 2998-3006.

Delvig, A., Jahn, S., Kusecek, B., Heckels, J. E., Rosenqvist, E., Høiby, E. A., Michaelsen, T. E. \& Achtman, M. (1994). A comparison of human and murine monoclonal IgGs specific for the P1.7 PorA protein of Neisseria meningitidis. Mol Immunol 31, 1257-1267.

Dempsey, J. A. F., Litaker, W., Madhure, A., Snodgrass, T. L. \& Cannon, J. G. (1991). Physical map of the chromosome of Neisseria gonorrhoeae FA1090 with locations of genetic markers, including opa and pil genes. J Bacteriol 173, 5476-5486.

Dempsey, J. A. F., Wallace, A. B. \& Cannon, J. G. (1995). The physical map of the chromosome of a serogroup A strain of Neisseria meningitidis shows complex rearrangements relative to the chromosomes of two mapped strains of the closely related species N. gonorrhoeae. J Bacteriol 177, 6390-6400. 
Geysen, H. M., Rodda, S. J., Mason, T. J., Tribbick, G. \& Schoofs, P. G. (1987). Strategies for epitope analysis using peptide synthesis. J Immunol Methods 102, 259-274.

Hobbs, M. M., Seiler, A., Achtman, M. \& Cannon, J. G. (1994). Microevolution within a clonal population of pathogenic bacteria: recombination, gene duplication and horizontal genetic exchange in the opa gene family of Neisseria meningitidis. Mol Microbiol 12, 171-180.

James, J. F. \& Swanson, J. (1978). Studies on gonococcus infection. XIII. Occurrence of color/opacity colonial variants in clinical cultures. Infect Immun 19, 332-340.

Jerse, A. E., Cohen, M. S., Drown, P. M., Wicker, L. G., Isbey, S. F., Seifert, H. S. \& Cannon, J. G. (1994). Multiple gonococcal opacity proteins are expressed during experimental urethral infection in the male. J Exp Med 179, 911-920.

Kawula, T. H., Aho, E. L., Barritt, D. S., Klapper, D. G. \& Cannon, J. G. (1988). Reversible phase variation of expression of Neisseria meningitidis class 5 outer membrane proteins and their relationship to gonococcal proteins II. Infect Immun 56, 380-386.

Kellogg, D. S., Peacock, W. L., Deacon, W. E., Brown, L. \& Pirkle, C. I. (1963). Neisseria gonorrhoeae. 1. Virulence genetically linked to clonal variation. J Bacteriol 85, 1274-1279.

Kriz, P., Lebedova, V. \& Musilek, M. (1994). New epidemiological situation in the Czech Republic due to Neisseria meningitidis C:2a:P1.2(P1.5). In Neisseria '94, Proceedings of the Ninth International Pathogenic Neisseria Conference, Winchester, UK, pp. 378-380. Edited by J. S. Evans, S. E. Yost, M. C. J. Maiden \& I. M. Feavers.

Kupsch, E.-M., Knepper, B., Kuroki, T., Heuer, L. \& Meyer, T. F. (1993). Variable opacity (Opa) outer membrane proteins account for the cell tropisms displayed by Neisseria gonorrboeae for human leukocytes and epithelial cells. EMBO J 12, 641-650.

McGuinness, B., Barlow, A. K., Clarke, I. N., Farley, J. E., Anilionis, A., Poolman, J. T. \& Heckels, J. E. (1990). Deduced amino acid sequences of class 1 protein (PorA) from three strains of Neisseria meningitidis. Synthetic peptides define the epitopes responsible for serosubtype specificity. J Exp Med 171, 1871-1882.

Maiden, M. C. J., Malorny, B. \& Achtman, M. (1996). A global gene pool in the neisseriae. Mol Microbiol 21, 1297-1298.

Makino, S., van Putten, J. P. M. \& Meyer, T. F. (1991). Phase variation of the opacity outer membrane protein controls invasion by Neisseria gonorrhoeae into human epithelial cells. EMBO J 10, 1307-1315.

Morelli, G., del Valle, J., Lammel, C. J. \& 8 other authors (1994). Immunogenicity and evolutionary variability of epitopes within IgA1 protease from serogroup A Neisseria meningitidis. Mol Microbiol 11, 175-187.

Morelli, G., Malorny, B., Muller, K., Seiler, A., Wang, J., del Valle, J. \& Achtman, M. (1997). Clonal descent and microevolution of during 30 years of epidemic spread. Mol Microbiol 25, 1047-1064.

Murphy, G. L., Connell, T. D., Barritt, D. S., Koomey, M. \& Cannon, J. G. (1989). Phase variation of gonococcal protein II: regulation of gene expression by slipped-strand mispairing of a repetitive DNA sequence. Cell 56, 539-547.

Olyhoek, T., Crowe, B. A. \& Achtman, M. (1987). Clonal population structure of Neisseria meningitidis serogroup A isolated from epidemics and pandemics between 1915 and 1983. Rev Infect Dis 9, 665-692.

O'Rourke, M. \& Spratt, B. G. (1994). Further evidence for the nonclonal population structure of Neisseria gonorrboeae: extensive genetic diversity within isolates of the same electrophoretic type. Microbiology 140, 1285-1290.
Peltola, H. (1983). Meningococcal disease: still with us. Rev Infect Dis 5, 71-91.

Pinner, R. W., Gellin, B. G., Bibb, W. F. \& 8 other authors (1991). Meningococcal disease in the United States - 1986. J Infect Dis 164, 368-374.

Rest, R. F., Lee, N. \& Bowden, C. (1985). Stimulation of human leukocytes by protein $\mathrm{II}^{+}$gonococci is mediated by lectin-like gonococcal components. Infect Immun 50, 116-122.

Robinson, E. N., Clemens, C. M., McGee, Z. A. \& Cannon, J. G. (1988). Immunoelectron microscopic localization of outer membrane proteins II on the surface of Neisseria gonorrboeae. Infect Immun 56, 1003-1006.

Sacchi, C. T., Zanella, R. C., Caugant, D. A., Frasch, C. E., Hidalgo, N. T., Milagres, L. G., Pessoa, L. L., Ramos, S. R., Camargo, M. C. C. \& Melles, C. E. A. (1992). Emergence of a new clone of serogroup C Neisseria meningitidis in Sao Paulo, Brazil. J Clin Microbiol 30, 1282-1286.

Spratt, B. G., Smith, N. H., Zhou, J., O'Rourke, M. \& Feil, E. (1995). The population genetics of the pathogenic Neisseria. In Population Genetics of Bacteria (Society for General Microbiology Symposium 41), pp. 143-160. Edited by S. Baumberg, J. P. W. Young, J. R. Saunders \& E. M. H. Wellington. Cambridge: Cambridge University Press.

Stern, A. \& Meyer, T. F. (1987). Common mechanism controlling phase and antigenic variation in pathogenic neisseriae. Mol Microbiol 1, 5-12.

Stern, A., Brown, M., Nickel, P. \& Meyer, T. F. (1986). Opacity genes in Neisseria gonorrboeae: control of phase and antigenic variation. Cell 47, 61-71.

Suker, J., Feavers, I. M., Achtman, M., Morelli, G., Wang, J. \& Maiden, M. C. J. (1994). The porA gene in serogroup A meningococci : evolutionary stability and mechanism of genetic variation. Mol Microbiol 12, 253-265.

Swanson, J., Barrera, J., Sola, J. \& Boslego, J. (1988). Expression of outer membrane protein II by gonococci in experimental gonorrhoea. J Exp Med 168, 2121-2129.

Virji, M., Makepeace, K., Ferguson, D. J. P., Achtman, M. \& Moxon, E. R. (1993). Meningococcal Opa and Opc proteins : their role in colonization and invasion of human epithelial and endothelial cells. Mol Microbiol 10, 499-510.

Wang, J., Caugant, D. A., Li, X., Hu, X., Poolman, J. T., Crowe, B. A. \& Achtman, M. (1992). Clonal and antigenic analysis of serogroup A Neisseria meningitidis with particular reference to epidemiological features of epidemic meningitis in China. Infect Immun 60, 5267-5282.

Wang, J., Caugant, D. A., Morelli, G., Koumaré, B. \& Achtman, M. (1993). Antigenic and epidemiological properties of the ET-37 complex of Neisseria meningitidis. J Infect Dis 167, 1320-1329.

Weel, J. F., Hopman, C. T. \& van Putten, J. P. M. (1991). In situ expression and localization of Neisseria gonorrhoeae opacity proteins in infected epithelial cells : apparent role of Opa proteins in cellular invasion. J Exp Med 173, 1395-1405.

Woods, J. P. \& Cannon, J. G. (1990). Variation in expression of class 1 and class 5 outer membrane proteins during nasopharyngeal carriage of Neisseria meningitidis. Infect Immun 58, 569-572.

Received 6 August 1997; accepted 17 September 1997 